\title{
Kinetic organization of metaphase I bivalents in spermatogenesis of Lepidoptera and Trichoptera species with small chromosome numbers
}

\author{
KLAUS WERNER WOLF $\dagger$, KAREL NOVÁK $\$$ \& FRANTIŠEK MAREC* $\ddagger$ \\ $\dagger$ Institut für Anatomie der Medizinischen Universität, Ratzeburger Allee 160, D-23538 Lübeck, Germany and \\ $\ddagger$ Institute of Entomology, Czech Academy of Sciences, Branišovská 31, CZ-37005 České Budejovice, Czech Republic
}

\begin{abstract}
The fine structure of bivalents in metaphase I spermatocytes of two Lepidoptera species, Orgyia thyellina Butler $(n=11)$ and O. antiqua (L.) $(n=14)$ (Lymantriidae), and a Trichoptera species, Limnephilus decipiens (Kolenatý) $(n=10)$ (Limnephilidae) were studied using a series of ultrathin sections and transmission electron microscopy. The bulk of species in both orders possess a haploid chromosome number of about 30. Thus, the experimental species have relatively small chromosome numbers. This study showed that metaphase I bivalents in both Lepidoptera species are polykinetic; attachment of kinetochore microtubules is found scattered throughout the entire poleward chromosomal surface. The microtubules were inserted in material of medium electron density. A pair of distinct kinetochore plates, consisting of material of about the same electron density as the chromatin, was detected at each poleward chromosomal surface in metaphase I bivalents of the caddis-fly, $L$. decipiens. The observations suggest that DNA elements responsible for the organization of the kinetochores are dispersed throughout the chromosomes in the two Lepidoptera species, whereas they are narrowly clustered in the Trichoptera. Thus, karyotype evolution in the closely related Lepidoptera and the Trichoptera involved widely differing mechanisms.
\end{abstract}

Keywords: karyotype evolution, kinetochores, meiosis, microtubules.

\section{Introduction}

The insect orders Lepidoptera and Trichoptera are considered sister groups on the basis of about 20 synapomorphies, common characteristics derived from a common ancestor (Kobayashi \& Ando, 1988; Kristensen, 1991; Neboiss, 1991; Nielsen \& Common, 1991). Several synapomorphies also apply to properties of the karyotype. In both orders, females are the heterogametic sex and female meiosis is of the achiasmatic type (Suomalainen, 1966; Traut \& Mosbacher, 1968). Fine structure studies involving two Lepidoptera species, the Mediterranean flour moth Ephestia kuehniella (Wolf \& Traut, 1991) and the silkworm Bombyx mori (Holm \& Rasmussen, 1980), and a Trichoptera species, Anabolia furcata (Wolf et al., 1992) revealed that the architecture of bivalents in metaphase I spermatocytes is very similar. In all cases, two distinct kinet-

*Correspondence. E-mail: marec@entu.cas.cz ochores were found at each poleward surface of the chromosomes. The kinetochores consisted of plates of medium electron density that were in contact with microtubules (MTs). Ephestia kuehniella (Pyralidae) and B. mori (Bombycidae) have a haploid chromosome number of 30 and 28 , respectively (Traut \& Mosbacher, 1968; Traut, 1976; Holm \& Rasmussen, 1980). The caddis-fly, $A$. furcata (Limnephilidae), has not been precisely karyotyped, but published micrographs of a chromosome spread suggest that the haploid chromosome number is around 30 (fig. 5 in Wolf et al., 1992). Similarity between representatives of both insect groups with about 30 chromosomes is not restricted to chromosome structure in meiosis. In metaphase spermatogonia, kinetochore plates cover around 40 per cent of the chromosomal length (Gassner \& Klemetson, 1974; Wolf et al., 1992).

Information on the kinetic organization of chromosomes in Lepidoptera and Trichoptera species with exceptionally small chromosome 
numbers is scarce. In any case, electron microscopy is required because Lepidoptera chromosomes are unusually small (Goodpasture, 1975). In a previous fine structure study, the presence of polykinetic metaphase I bivalents has been mentioned in Orgyia thyellina Butler (Lymantriidae), a moth with a haploid set of 11 chromosomes (Wolf et al., 1987). In other words, MT contacts were found scattered throughout the entire poleward surface of the chromosomes. The emphasis of the study was, however, on the comparison of eupyrene and apyrene meiosis and chromosome structure was not documented in detail. In brief, Lepidoptera show double spermatogenesis. Eupyrene meiosis gives rise to spermatids which transform into fertilizing sperm, whereas apyrene meiosis leads to a non-fertilizing sperm variety (Meves, 1903; Wolf, 1994). In the present article, which is only concerned with eupyrene meiosis, we dwell on the kinetic organization of metaphase bivalents in primary spermatocytes of $O$. thyellina. In addition, we present information about bivalent structure in eupyrene spermatogenesis of another species of the same genus, $O$. antiqua (L.), which possesses a haploid set of 14 chromosomes (Cretschmar, 1928). Also in this species, spindle fine structure has been previously described (Wolf, 1990), but information on the kinetic organization of the bivalents is missing. Because only eupyrene spermatocytes are involved, we dispense with this attribute in the text when Lepidoptera are addressed. The findings in the Lepidoptera species are compared with those in a Trichoptera species, Limnephilus decipiens (Kolenatý) (Limnephilidae), with a haploid set of 10 chromosomes (Klingstedt, 1931; for a compilation of chromosome numbers in the Trichoptera, see Lankhorst, 1970).

\section{Materials and methods}

\section{Animals}

Wild-type last instar larvae of $O$. thyellina and $O$. antiqua were kindly provided by Sir Cyril A. Clarke (Liverpool, UK) (cf. Wolf et al., 1987; Wolf, 1990). Prior to preparation, the animals were maintained for several days in the laboratory and fed with hawthorn (Crataegus oxyacantha).

Second to third instar larvae of $L$. decipiens were collected in 'Domin' pond near České Budějovice in May 1993, maintained in an aquarium and fed with reed leaves (Phragmites communis), lettuce leaves (Lactuca sativa), and dead cricket larvae (Gryllus domesticus). At the beginning of June, fully grown larvae were placed in the refrigerator to prevent pupation, and then transferred in a highly humid atmosphere for dissection to Lübeck. In this species, which undergoes imaginal diapause in native conditions (Novák \& Sehnal, 1963), the larvae approaching pupation appeared to be optimal for preparation of meiotic chromosomes in metaphase I (cf. Le Lannic, 1975).

\section{Preparation for electron microscopy}

The preparation procedure has been described previously (Wolf, 1994). In brief, the dissected gonads were transferred to Ringer solution (Glaser, 1917: cited by Lockwood, 1961) containing 2.5 per cent glutaraldehyde. The composition of the Ringer solution was: $9 \mathrm{~g} \mathrm{NaCl}, 0.42 \mathrm{~g} \mathrm{KCl}, 0.25 \mathrm{~g} \mathrm{CaCl}_{2}$ and $0.2 \mathrm{~g} \mathrm{NaHCO}_{3}$ per litre doubly distilled water. After $5 \mathrm{~min}$, three volumes of 8 per cent tannic acid (Merck) in phosphate buffer $(0.067 \mathrm{~m}, \mathrm{pH}$ 6.8) were added. The gonads were postfixed in phosphatebuffered $\mathrm{OsO}_{4}$ (1 per cent), dehydrated in ethanol and embedded in Epon 812. Ultrathin sections, about $70 \mathrm{~nm}$ thick, were mounted on Pioloformcoated grids, doubly stained with uranyl acetate and lead citrate and analysed with a Philips EM 400 transmission electron microscope operated at $80 \mathrm{kV}$.

In $O$. thyellina, one longitudinally sectioned and one cross-sectioned metaphase I plate have been recorded using series of consecutive sections. In $O$. antiqua and $L$. decipiens, it has been one longitudinally sectioned metaphase I spindle in each. In all cases, primary spermatocytes were studied, and the findings were confirmed by inspection of about six neighbouring cells of the same developmental stage and taken from the same cyst.

\section{Results}

\section{Orgyia thyellina}

The fine structure of metaphase I spermatocytes of $O$. thyellina has been described previously. In brief, the spindle area was surrounded by a multilayered sheath of membranes structurally reminiscent of agranular (smooth) endoplasmic reticulum (ER). Membranous elements were also scattered throughout the spindle area. The spindle poles were marked by pairs of basal bodies continuous with flagella (Wolf et al., 1987). In the present study, the kinetic organization of bivalents was analysed in a serially cross-sectioned metaphase I spindle. A total of 11 chromosomes could be identified as individuals and they were very similar. Serial cross-sections through the poleward surface of one bivalent, situated in the spindle periphery, are depicted (Fig. 1a-i). At least five major kinetochore MT bundles were in contact 

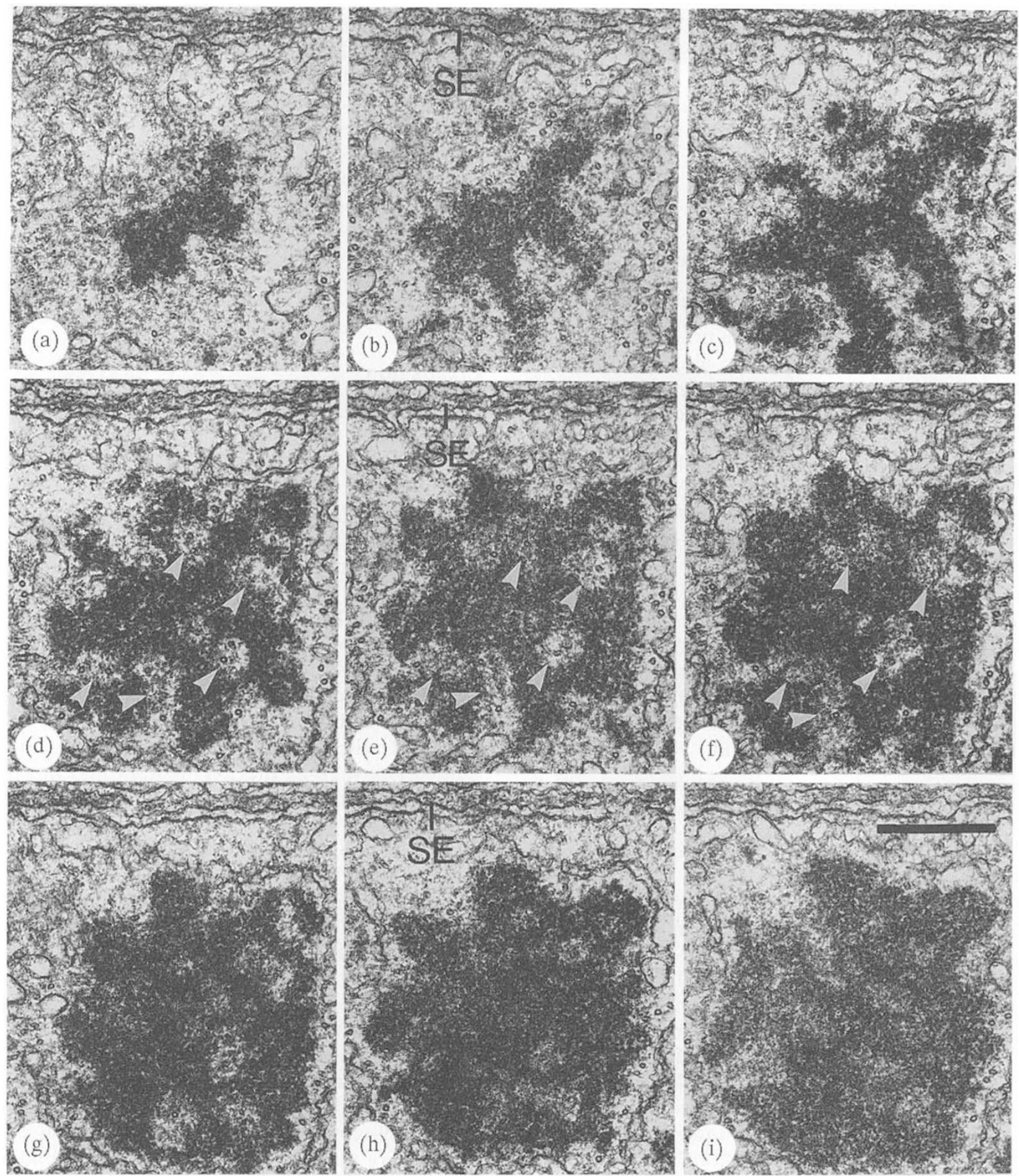

Fig. 1 (a-i) Transmission electron micrographs of nine consecutive serial sections through the poleward chromosomal surface of a metaphase bivalent of Orgyia thyellina. The section plane is at right angles to the spindle axis. The proximity of the spindle envelope (SE), which consists of membrane stacks, signals that the bivalent lies in the spindle periphery. Several major bundles of microtubules (arrowheads) penetrate into the chromatin. Note cross-sectioned spindle microtubules and intraspindle membranes lateral to the bivalent. (Bar represents $0.5 \mu \mathrm{m}$.) 
with the poleward chromosomal surface. The MTs penetrated up to seven sections, about $500 \mathrm{~nm}$, into the chromatin. Material of lesser electron density was found at the MT ends. The MT ends were scattered throughout the chromosomal surface. Thus, the previous assessment that bivalents in male meiosis of $O$. thyellina are polykinetic (Wolf et al., 1987) has been confirmed.

\section{Orgyia antiqua}

The overall architecture of metaphase I spermatocytes of $O$. antiqua and, in particular, the structure of the spindles were very similar to that in $O$. thyellina (cf. Wolf, 1990). There was a prominent layer of perispindle membranes and also intraspindle membranes were abundant. Longitudinal serial sections through metaphase I spindles were inspected in order to determine the kinetic organization of the bivalents. These never showed lateral contacts with one another. Independent of the size, the chromosomes were very similar. MT bundles were attached to the poleward chromosomal surfaces. A preferential location of the MT ends was not detectable. The MT ends were scattered throughout the entire surface. The MT ends were embedded in material of lesser electron density. At several sites, threads of electron-dense chromatin extended for $400-600 \mathrm{~nm}$ from the chromosomal surfaces (Fig. 2a-1). As in O. thyellina, this indicates that the MTs penetrate into the chromatin.

\section{Limnephilus decipiens}

The analysis of serial longitudinal sections through metaphase I spindles in testes of the caddis-fly revealed a conventional bipolar spindle apparatus. Spindle-associated membranes were scarce. Only few membranous sheets reminiscent of the smooth ER were found. In contrast with the Lepidoptera species described above, the bivalents showed a few lateral contacts. Nevertheless, most chromosomes could be identified as individuals. Independent of the sizes of the bivalents the kinetic organization was very similar. As a rule, the chromosome surfaces were relatively smooth. The individual bivalents possessed two distinct kinetochore plates at each poleward surface, representing the kinetic apparatus of two sister chromatids. Thus, each bivalent showed a total of four kinetochore plates. In small bivalents, the centre-to-centre distance between the individual kinetochore plates of the sister chromatids was about $600 \mathrm{~nm}$ (Fig. 3a-d). In large bivalents, this distance was up to $1.3 \mu \mathrm{m}$ (Fig. $4 \mathrm{a}-\mathrm{d}$ ). The kinet- ochore plates laid in shallow recesses of the chromatin. Although they showed about the same electron density as the chromatin, the kinetochore plates could be readily distinguished, because they were separated by a transparent gap from the underlying chromatin. The kinetochore plates were disc-shaped with a diameter of $200-250 \mathrm{~nm}$. An inner kinetochore layer, as we know it from mammalian kinetochores (cf. Rieder, 1982), was, however, not observed in bivalents of the caddis-fly. The kinetochore plates were in contact with MT bundles. The chromosomal surfaces, laterally located with respect to the kinetochore plates, were largely devoid of MT contacts.

\section{Discussion}

Bivalent structure in male meiosis of Lepidoptera and Trichoptera species with chromosome numbers around 30 is very similar. Each poleward chromosomal surface possesses two individual kinetochore plates and MTs are connected with the material. The kinetochore plates are, however, slightly less distinct in the Lepidoptera (Holm \& Rasmussen, 1980; Wolf \& Traut, 1991; Wolf et al., 1992). Lepidoptera and Trichoptera are considered monophyletic sister groups (Kobayashi \& Ando, 1988). It is therefore a strong possibility that the common ancestors of the Lepidoptera and Trichoptera shared the bivalent architecture described above. A similarity of the commonest haploid chromosome numbers, $n=31$ in the Lepidoptera and $n=30$ in the Trichoptera, was interpreted as another synapomorphic trait of the sister groups (Suomalainen, 1966, 1969). Indeed, chromosomal variance in the Lepidoptera shows a marked mode at 28-31 throughout most families (Suomalainen, 1969; Robinson, 1971; White, 1973). Representatives of the most primitive lepidopteran families do not differ from the others in this respect $(n=31-32$; Suomalainen, 1969). Identification of the type chromosome number in the Trichoptera appears, however, incorrect. Kiauta (1971) argued that the number of $n=30$ cannot be regarded as the true type number of Trichoptera, although it was most frequently reported. In fact, the $n=30$ complement is typical of the most advanced family Limnephilidae but has not been found in any other family examined so far (see Lankhorst, 1970). On the other hand, relatively high chromosome numbers, ranging from $n=22$ to $n=30$, predominate in most studied families of the suborder Integripalpia, although low numbers also occur. The other suborder, Annulipalpia, with only three species karyotyped shows low 

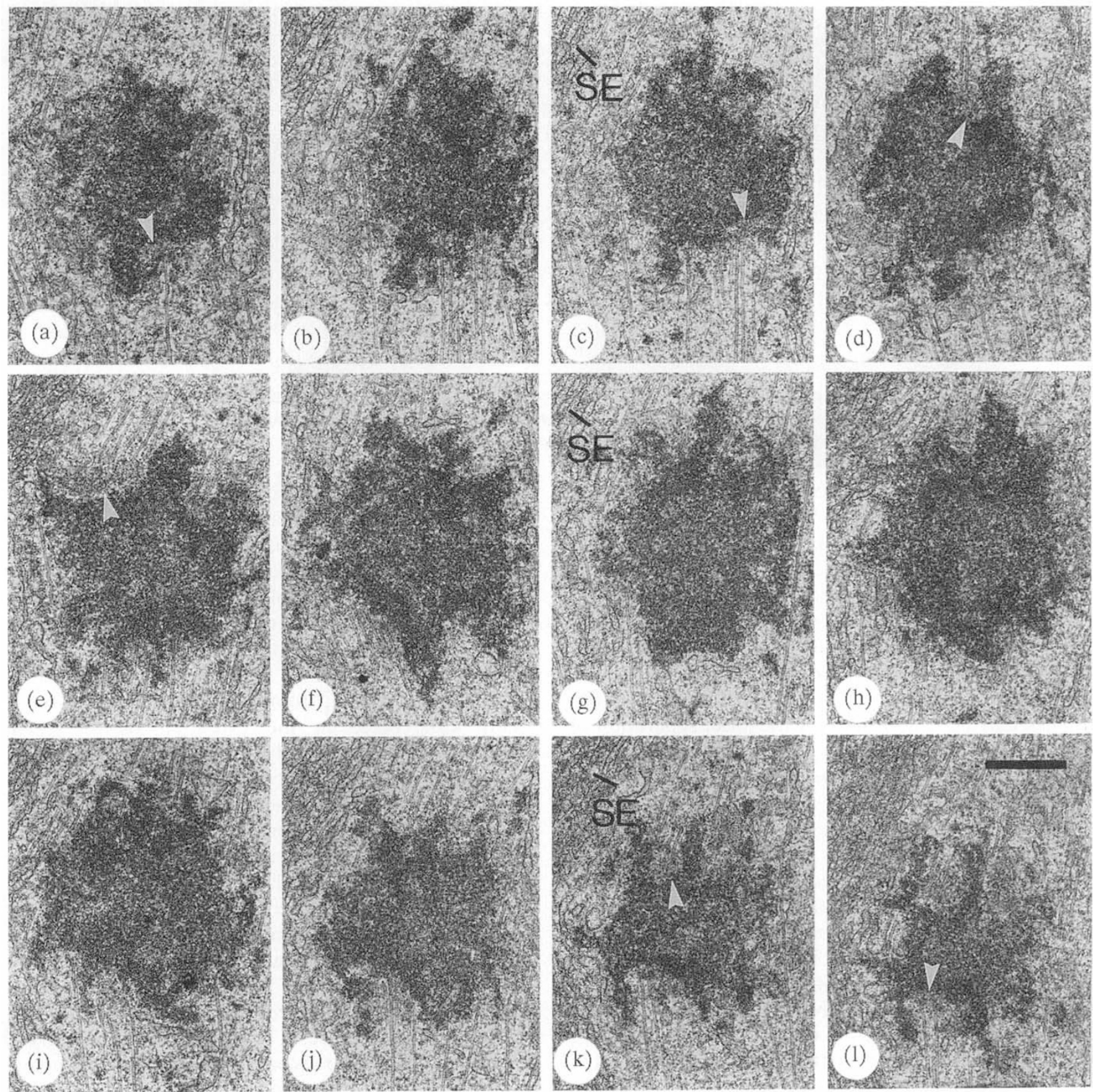

Fig. 2 (a-l) Transmission electron micrographs of 12 consecutive serial sections through a metaphase bivalent of Orgyia antiqua. The section plane is in parallel to the spindle axis and the bivalent is situated in the spindle periphery as indicated by the spindle envelope (SE). Material of lesser electron density than the chromatin is found at various sites on both chromosomal surfaces (arrowheads). Microtubules are in contact with the material. (Bar represents $0.5 \mu \mathrm{m}$.)

chromosome numbers, $n=13$ and $n=15$ (see the Ross' phylogenetic tree of Trichoptera in Kiauta, 1971). Taken together, it is likely that the common ancestor of the Trichoptera and Lepidoptera had a high haploid chromosome number close to 30 . Hence, low numbers of chromosomes, in particular in the Trichoptera, could have repeatedly evolved as a derived character in different families.

The divergence of the two orders involved a series of changes. Higher Lepidoptera, for example, form two morphologically and functionally different sperm types (Meves, 1903; Wolf, 1994), whereas the 

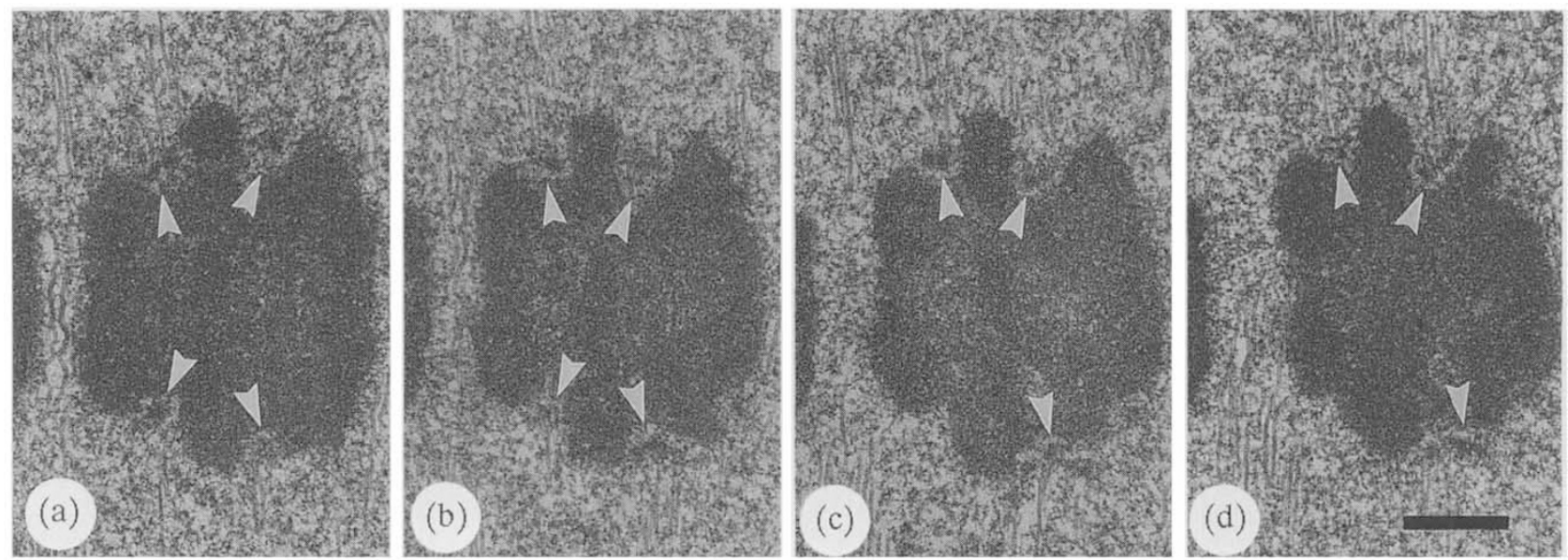

Fig. 3 (a-d) Transmission electron micrographs of four consecutive serial sections through a small metaphase I bivalent of Limnephilus decipiens. The section plane is in parallel to the spindle axis. A pair of kinetochore plates (arrowheads) is attached to each poleward chromosomal surface. (Bar represents $0.5 \mu \mathrm{m}$.)

most primitive Lepidoptera and all Trichoptera produce only one sperm type (Friedländer, 1983; Sonnenschein \& Häuser, 1990; Hamon \& Chauvin, 1992). At the cellular level, meiotic spindles in male Lepidoptera show an abundant set of spindle-associated membranes, whereas the Trichoptera spindles have a relatively poor membrane inventory. The abundance of intraspindle membranes, which is typical of male meiosis in the Lepidoptera (Wolf, 1995), may be responsible for the strict separation of the individual bivalents in metaphase I spindles of $O$. thyellina and $O$. antiqua. The poor intraspindle membrane system of $L$. decipiens renders it possible that chromosomes laterally associate with one another.

The present study showed another diverging cellular trait: the kinetic organization of metaphase I bivalents in male meiosis of representatives with small chromosome numbers. The bivalents of two Lepidoptera species, $O$. thyellina and $O$. antiqua with $n=11$ and 14 , respectively, were polykinetic. MTs were found connected with the entire poleward chromosomal surface. Attachment sites of MTs consisted of material of lesser electron density than the chromatin, and were situated in relatively deep recesses of the chromosomal surface. Distinct kinetochore plates as shown in E. kuehniella (Gassner \& Klemetson, 1974; Wolf \& Traut, 1991) were, however, not detected. Our interpretation of the polykinetic organization is illustrated in Fig. 5a. Each chromatid carries several attachment sites which are distributed throughout their surface. In the metaphase I bivalent, the chromatids are probably wound or somehow folded to expose the attachment sites to MTs. This arrangement could explain the roughly spherical appearance of the bivalents as well as their irregular surface in longitudinal sections. We suggest that the polykinetic organization in the two Orgyia species examined could evolve from originally localized kinetochores of their ancestor with the haploid chromosome number around 30; such numbers were reported for three other species of the same genus, $O$. ericae and $O$. recens $(n=30)$ and $O$. leucostigma $(n=28)$ (see Robinson, 1971). Chromosome fusions most probably took place in the evolution of the small chromosome numbers of $O$. antiqua and $O$. thyellina (cf. Suomalainen, 1969). Then, polykinetic organization of the neochromosomes could be established provided that the chromosome fusions were not followed either by further rearrangements leading to fusions of kinetochore plates or inactivation of additional kinetochores. In contrast to the two Lepidoptera, metaphase I bivalents of the Trichoptera species, L. decipiens, with a haploid set of 10 chromosomes showed two distinct kinetochores located in shallow recesses at each poleward chromosomal surface. The two sites represent the kinetochores of two sister chromatids (for a scheme, see Fig. 5b). A very similar kinetic organization has been described in another limnephilid, A. furcata, which has, however, $n \approx 30$ (Wolf et al., 1992). The high number of chromosomes is characteristic for Limnephilidae, found in five of the 10 examined species of the genus Limnephilus; whereas it varies from 6 to 16 in the other five species (Lankhorst, 1970; Kiauta, 1971). One can, therefore, expect that the low chromosome number in $L$. decipiens represents, similar to $O$. antiqua and $O$. thyellina, a derived character. In this case, however, genome rearrangements leading to the reduction of chromosome number did not result in a polykinetic organi- 

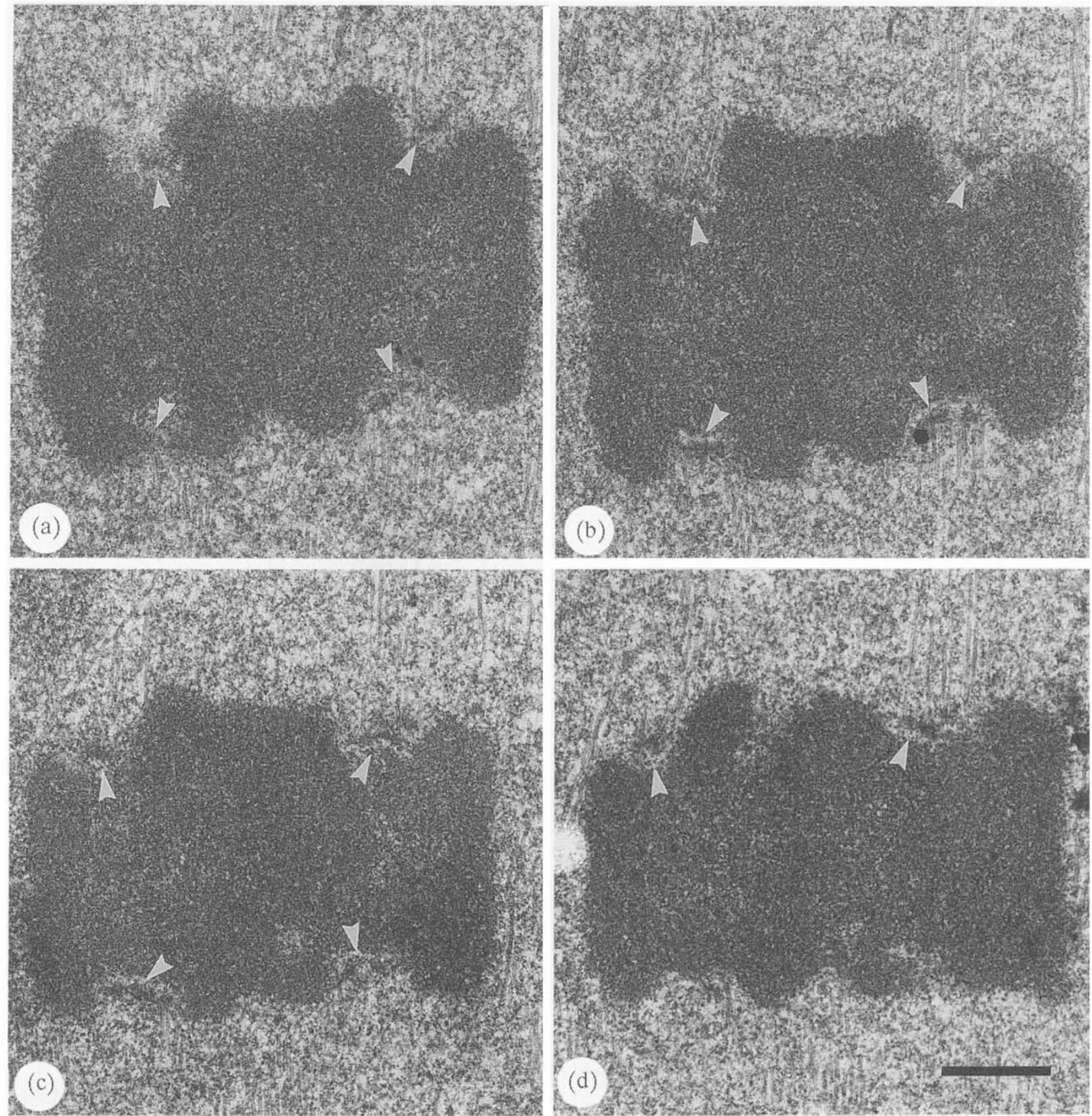

Fig. 4 (a-d) Transmission electron micrographs of four consecutive serial sections through a large metaphase I bivalent of Limnephilus decipiens. The section plane is in parallel to the spindle axis. A pair of kinetochore plates (arrowheads) is attached to each poleward chromosomal surface. (Bar represents $0.5 \mu \mathrm{m}$.)

zation of the chromosomes. Thus, in karyotype evolution of the Trichoptera the putative ancestral type of kinetic organization (see above) was conserved, while the Lepidoptera developed a novel type.

In mammalian cells, kinetochores are organized by specific DNA elements (Choo et al., 1991) and this appears to be the case also in insects. The number of centromere-specific DNA sequences, detected in this group, is increasing (for a review, see Wolf, 1996). As a rule, the centromere-associated DNA is repetitive. It is plausible to assume that species-specific repetitive DNA is also involved in the formation of kinetochores in the Lepidoptera and Trichoptera. The highly diverging appearance of the kinetochores in the species examined in the present study suggests far-reaching differences in the distribution of the underlying DNA along the

(C) The Genetical Society of Great Britain, Heredity, 79, 135-143. 


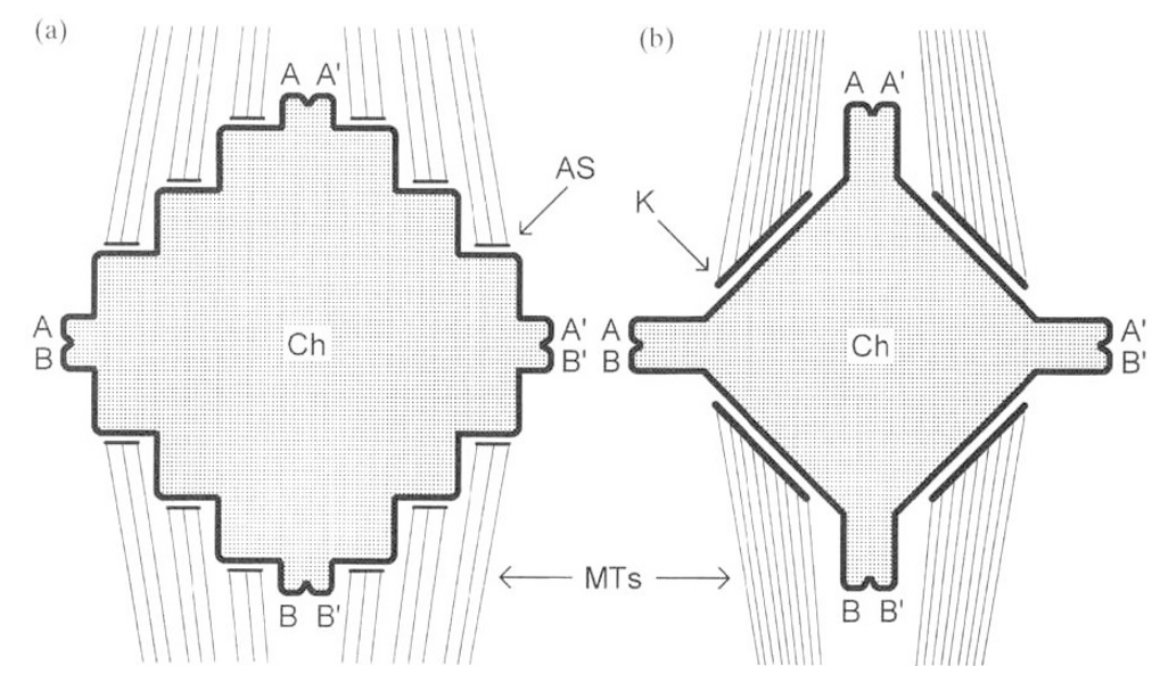

Fig. 5 Schematic drawings of two metaphase I bivalents with different kinetic organization. (a) A proposed structure of a bivalent with polykinetic organization, the situation found in two Lepidoptera species, Orgyia thyellina and $O$. antiqua. (b) Structure of a bivalent with the putative ancestral type of kinetic organization (see the text for details), showing localized, relatively large kinetochores. $\mathrm{A}$ and $\mathrm{A}^{\prime}, \mathrm{B}$ and $\mathrm{B}^{\prime}$, the poleward surface of two sister chromatids of two homologous chromosomes; AS, attachment site of microtubules; Ch, chromatin; K, kinetochore plate; M'Ts, microtubules of the spindle.

chromosomes. It is clustered in the Trichoptera and highly dispersed in the Lepidoptera. Thus, karyotype evolution in the Lepidoptera and Trichoptera differed widely. This is also apparent in the variability of the chromosome numbers. Whereas Trichoptera show moderate variation - the smallest and the highest chromosome numbers are 6 and 30 , respectively, (Kiauta, 1971) - the Lepidoptera have a larger range in chromosome number than any other animal group (from $n=7$ to $n=\mathrm{c}$. 220) (Robinson, 1971; White, 1973; cf. also Wolf, 1994). Thus, dispersion of centromere-specific DNA is likely to render chromosomes more susceptible to or tolerant of karyotype rearrangements.

The appearance of the large metaphase I bivalents in $L$. decipiens is informative, because the individual kinetochore plates at the poleward chromosomal surface were up to $1.3 \mu \mathrm{m}$ apart from one another. Principally the chromosomes are dicentric. Although transmissible dicentric chromosomes have been described (Ault \& Lyttle, 1988; Wandall, 1994), this condition is usually correlated with a high rate of chromosome breakage and segregation. The reason for this behaviour lies in the risk that the two kinetochores of one poleward surface become oriented towards opposite spindle poles in metaphase. Spindle forces consequently tear the chromosome apart. In the case of the Trichoptera chromosomes, however, either the distance between the individual kinetochores is too small and/or the chromosomes are too stiff to allow this kind of orientation. Inacti- vation of centromeres, which has been observed in dicentric chromosomes of mammals (Earnshaw \& Migeon, 1985), can be ruled out in the present case, because MTs were associated with both kinetochores.

\section{Acknowledgements}

The authors are grateful Mrs S. Glatzel and Mrs F. Niedereichholz for excellent technical assistance. The work was supported by the 'Deutsche Forschungsgemeinschaft' (Wo 394/6-1). FM was supported by the grant no. A607105 and its renewal no. A6007609 of the Czech Academy of Sciences.

\section{References}

AUlt, J. G. AND LytTle, T. w. 1988. A transmissible dicentric chromosome in Drosophila melanogaster. Chromosoma, 97, 71-79.

CHOO, K. H., VISSEL, B., NAGY, A., EARLE, E. AND KALITSIS, P. 1991. A survey of the genomic distribution of alpha satellite DNA on all the human chromosomes, and derivation of a new consensus sequence. Nucl. Acids Res., 19, 1179-1182.

CRETSCHMAR, M. 1928. Das Verhalten der Chromosome bei der Spermatogenese von Orgyia thyellina Btl. und antiqua L., sowie eines ihrer Bastarde. Z. Zellforsch. Mikrosk. Anat., 7, 291-399.

EARNSHAW, W. C. AND MIGEON, B. R. 1985. Three related centromere proteins are absent from the inactive centromere of a stable isodicentric chromosome. Chromosoma, 92, 290-296.

(c) The Genetical Society of Great Britain, Heredity, 79, 135-143. 
FRIEDLÄNDER, M. 1983. Phylogenetic branching of Trichoptera and Lepidoptera: An ultrastructural analysis on comparative spermatology. J. Ultrastruct Res., 83, 141-147.

GASSNER, G. AND KLEMETSON, D. J. 1974. A transmission electron microscope examination of Hemipteran and Lepidopteran gonial centromeres. Can. J. Genet. Cytol., 16, $457-464$.

GOODPASTURE, c. 1975. High-resolution chromosome analysis in Lepidoptera. Ann. Entomol. Soc. Am., 69, 537-544.

HAMON, C. AND CHAUVIN, G. 1992. Ultrastructural analysis of spermatozoa of Korscheltellus lupulinus L. (Lepidoptera: Hepialidae) and Micropterix calthella L. (Lepidoptera: Micropterigidae). Int. J. Insect Morphol. Embryol., 21, 149-160.

HOLM, P. B. AND RASMUSSEN, s. w. 1980. Chromosome pairing, recombination nodules and chiasma formation in diploid Bombyx males. Carlsberg Res. Comm., 45, 483-548.

K1AUTA, B. 1971. The chromosome condition in the spermatogenesis of the caddis-fly Goera pilosa (Fabricius, 1775) (Trichoptera, Integripalpia, Limnephiloidea: Goeridae) from the God dal Fuorn in the Swiss National Park, with considerations on the phylogenetic position of the family. Ergeb. Wiss. Untersuch. Schweiz. Natl.-Park., 9, 174-185.

KLINGSTEDT, H. 1931. Digametie beim Weibchen der Trichoptere Limnophilus decipiens Kol. nebst Erörterungen zur Theorie der Geschlechtsvererbung. Acta Zool. Fenn., 10, 1-64.

KOBAYASHI, Y. AND ANDO, H. 1988. Phylogenetic relationships among the lepidopteran and trichopteran suborders (Insecta) from the embryological standpoint. $Z$. Zool. Syst. Evolut.-forsch., 26, 186-210.

KRISTENSEN, N. P. 1991. Phylogeny of extant Hexapods. In: Naumann, I. D., Carne, P. B., Lawrence, J. F., Nielsen, E. S., Spradbery, J. P., Taylor, R. W. et al. (eds) The Insects of Australia, 2nd edn, vol, 1, pp. 125-140. Melbourne University Press, Carlton, Victoria, Australia.

LANKHORST, L. 1970. A note on the periodicity of cell divisions in the gonads of Trichoptera, with a review of the main cytotaxonomic data on the caddis-fly species so far studied. Genen Phaenen, 14, 9-14.

LE LANNIC, J. 1975. Contribution à l'étude du développment et de la maturation de l'appareil reproducteur de Limnephilus rhombicus L. Bull. Soc. Zool. Fr., 100, 539-550.

LOCKWOOD,A. P. M. 1961. 'Ringer' solutions and some notes on the physiological basis of their ionic composition. Comp. Biochem. Physiol., 2, 241-289.

MEVES, F. 1903. über oligopyrene und apyrene Spermien und über ihre Entstehung nach Beobachtungen an Paludina und Pygaera. Arch. Mikrosk. Anat. Entwicklungsgesch., 61, 1-84.

NEBoIss, A. 1991. Trichoptera. (Caddis-flies, caddises). In: Naumann, I. D., Carne, P. B., Lawrence, J. F., Nielsen, E. S., Spradbery, J. P., Taylor, R. W. et al. (eds) The
Insects of Australia, 2nd edn, vol. 2, pp. 787-816. Melbourne University Press, Carlton, Victoria, Australia.

NIELSEN, E. S. AND COMMON, 1. F. B. 1991. Lepidoptera (moths and butterflies). In: Naumann, I. D., Carne, P. B., Lawrence, J. F., Nielsen, E. S., Spradbery, J. P., Taylor, R. W. et al. (eds) The Insects of Australia, 2nd edn, vol. 2, pp. 817-915. Melbourne University Press, Carlton, Victoria, Australia.

NOVÁK, K. AND SEHNAL, F. 1963. The development cycle of some species of the genus Limnephilus (Trichoptera). Acta Soc. Entomol. Čechoslov., 60, 68-80.

RIEDER, C. L. 1982. The formation, structure and composition of the mammalian kinetochore and kinetochore fiber. Int. Rev. Cytol., 79, 1-58.

Robinson, R. 1971. Lepidoptera Genetics. Pergamon Press, Oxford.

SONNENSCHEIN, M. AND HÄUSER, C. L. 1990. Presence of only eupyrene spermatozoa in adult males of the genus Micropterix Hübner and its phylogenetic significance (Lepidoptera: Zeugloptera, Micropterigidae). Int. J. Insect Morphol. Embryol., 19, 269-276.

suomalainen, E. 1966. Achiasmatische Oogonese bei Trichopteren. Chromosoma, 18, 201-207.

SuOMAlainen, E. 1969. Chromosome evolution in the Lepidoptera. Chromosomes Today, 2, 132-138.

TRAuT, w. 1976. Pachytene mapping in the female silkworm, Bombyx mori L. (Lepidoptera). Chromosoma, 58, 275-284.

TRAUT, w. AND MOSBACHER, G. C. 1968. Geschlechtschromatin bei Lepidopteren. Chromosoma, 25, 343-356.

WANDALL, A. 1994. A stable dicentric chromosome: Both centromeres develop kinetochores and attach to the spindle in monocentric and dicentric configuration. Chromosoma, 103, 56-62.

white,M. J. D. 1973. Animal Cytology and Evolution. Cambridge University Press, Cambridge.

wOLF, K. w. 1990. Sheathed nuclear division in primary spermatocytes of Orgyia antiqua (Lepidoptera, Insecta). BioSystems, 24, 5-15.

WOLF, K. w. 1994. The unique structure of Lepidopteran spindles. Int. Rev. Cytol., 152, 1-48.

wOLF, K. w. 1995. Spindle membranes and spindle architecture in invertebrates. Micron, 26, 69-98.

wOLF, K. w. 1996. The structure of condensed chromosomes in mitosis and meiosis of insects. Int. J. Insect Morphol. Embryol., 25, 37-62.

WOLF, K. W. AND TRAUT, w. 1991. Cytology of Lepidoptera. VII. The restructuring of eupyrene prophase I spermatocytes and its relationship to meiotic chromosome and spindle organization in Ephestia kuehniella Z. Protoplasma, 165, 51-63.

wOlF, K. w., BaUmgart, K. AND Traut, w. 1987. Cytology of Lepidoptera. II. Fine structure of eupyrene and apyrene primary spermatocytes in Orgyia thyellina. Eur. J. Cell Biol., 44, 57-67.

WOLF, K. W., NOVÁK, K. AND MAREC, F. 1992. Chromosome structure in spermatogenesis of Anabolia furcata (Trichoptera). Genome, 35, 46-52. 